\title{
Atypical Location of Osteoid Osteoma in Patients Referred to Orthopedic Hospital in Tabriz
}

\author{
Mostafa Ghavami1 , Hojjat Hossein-Pourfeizi ${ }^{2}{ }^{*}$, Mohammad-Hossein Biglu ${ }^{3}$ \\ ${ }^{1}$ Radiology Department, Paramedical Faculty, Tabriz University of Medical Sciences, Tabriz, Iran \\ ${ }^{2}$ Orthopedics Department, Medical Faculty, Tabriz University of Medical Sciences, Tabriz, Iran \\ ${ }^{3}$ Basic Sciences Department, Paramedical Faculty, Tabriz University of Medical Sciences, Tabriz, Iran \\ Email: mostafa.ghavami@yahoo.com, ^hojjat.pourfeizi@gmail.com, biglu@tbzmed.ac.ir
}

How to cite this paper: Ghavami, M., Hossein-Pourfeizi, H. and Biglu, M.-H. (2016) Atypical Location of Osteoid Osteoma in Patients Referred to Orthopedic Hospital in Tabriz. Open Access Library Journal, 3: e3096 http://dx.doi.org/10.4236/oalib.1103096

Received: September 27, 2016

Accepted: October 18, 2016

Published: October 21, 2016

Copyright $\odot 2016$ by authors and Open Access Library Inc.

This work is licensed under the Creative Commons Attribution International

License (CC BY 4.0)

http://creativecommons.org/licenses/by/4.0/

c) (i) Open Access

\begin{abstract}
Background: Osteoid osteoma is a painful bone tumor that usually affects long bones. The unusual location of osteoid osteoma is rare and may be misleading and misinterpreting the diagnosis. Objective: The objective of current study was to determine and explain the unusual cases of Osteoid osteoma found in atypical location (the coccyx, iliac bone, toe, vertebral body and scapula) of patients that were referred to our institution. Patients and Methods: We examined the imaging features: Plain Film, CT Scan, MRI, Scan isotope that could alert the radiologists toward a correct diagnosis. For reviewing the literature in the field, we extracted all publications indexed as a MeSH Major Topic of "osteoma, osteoid" in MEDLINE database via PubMed search engine throughout 2006-2015. We restricted our search to case reports. Results: We determined 5 patients with atypical location of osteoid osteoma in patients referred to our hospital during years 2014-2015. The literature review of osteoid osteoma in MEDLINE showed that, there have been only 134 rare case reports about osteoid osteoma which were published and indexed in MEDLINE during the last decade (2006-2015). The rarest of rare case reports for osteoid osteoma was in Maxilla, Nasal, Ribs, and Sarcrum. Conclusion: Analysis of our study concluded that the physicians should bear in mind, the probability of osteoid osteoma, when they are considering the chronic pain in the atypical areas of patients' body.
\end{abstract}

\section{Subject Areas}

Orthopedics, Radiology \& Medical Imaging

\section{Keywords}

Osteoid Osteoma, Bone Tumor, Vertebrae 


\section{Background}

Osteoid osteoma is a noncancerous bone tumor that usually occurs in the long bones of the body such as the femur (thighbone) and tibia (shinbone). Although the osteoid osteoma does not spread through the body, it shows side-effects that cause pain and discomfort in patients. Osteoid osteomas can affect people of all ages but the incidence among children is reported more frequent than adults. The osteoid osteoma appears predominantly in male patients. The cause of osteoid osteoma has stayed still unknown [1]. Since the first report of osteoid osteoma by Jaffe in 1935, many cases were reported from all over the world [2] [3]. In most cases, the patients report inflammatory-like pain that worsens at night which is alleviated with nonsteroidal anti-inflammatory drugs (NSAID) [4]. The occurrence of osteoid osteoma in flat bones rarely has been reported. The tumor is usually smaller than $1.5 \mathrm{~cm}$ in diameter and seldom is larger than $1.5 \mathrm{~cm}$ in diameter. Osteoid osteoma primarily appears as a small sclerotic bone island within a central nidus [5]. Computed tomography scan (CTS), bone scanning, and magnetic resonance imaging (MRI) have all evidenced beneficial techniques, when plain films fail to reveal a nidus [6]. The nidus shows a variable degree of mineralization, which may be amorphous, punctate, ring like, or in rare cases uniformly dense. The clinical diagnosis of osteoid osteoma in atypical location is often missed or delayed; this may be due to the fact that the radiological, clinical features of the tumor in atypical regions differ from those in long bones [7].

\section{Objective}

The objective of current study was to determine the rare location of osteoid osteoma in patients referred to the orthopedic hospital of Tabriz University of Medical Sciences during years 2014-2015. We determined 5 rare cases among patients, who were referred to our clinical center with a persistent dull pain at atypical location of osteoid osteoma. The average age of patients was 26.2 years (ranging from 20 - 33 years).

\section{Materials/Patients}

In this study two sets of data were analyzed: first, 5 unusual cases of osteoid osteoma found in atypical location (the coccyx, iliac bone, toe, vertebral body and scapula) of patients that were referred to our institution. We examined the imaging features Plain Film, CT Scan, MRI, Scan isotope that could alert the radiologists toward a correct diagnosis.

Second, all case reports indexed as a Mesh Major Topic of "osteoma, osteoid" in MEDLINE database during years 2006-2015 was extracted and analyzed.

\section{Results}

We searched the literature for osteoid osteoma in the database of MEDLINE using PubMed search engine with restricting the time span in a period of 10 years (20062015). We restricted our search into all case reports that was indexed as a Mesh Major Topic of "osteoma, osteoid" in MEDLINE. Retrieving of data led a total number of 261 
case reports about osteoid osteoma. After additional manual analysis, 134 were determined to meet the diagnostic criteria for the rare case reports of osteoid osteoma that were selected for statistical analysis (Table 1).

We determined 5 patients with atypical location of osteoid osteoma.

The first case: A 30 years old man presented with a 7-month history of pain in the left hip. Pain was worsening at night and was slightly improved by NSAID.

Plain radiographies showed increased bone density in the left acetabular roof (Figure 1(a)). A technetium $99 \mathrm{~m}$ bone scan showed focally increased uptake in the same region (Figure 1(b)). Computed Tomography (CT) of the pelvic revealed a hyperdense nidus of $10 \mathrm{~mm}$ in diameter (Figure 1(c), Figure 1(d)).

Clinical and imaging impression was a wound consistent with osteoid osteoma. The patient consequently went under the surgical excision of the nidus. The nidus was completely removed by curettage. Histological examination revealed an osteoid osteoma. After procedure the symptoms were totally relieved. One-year clinical follow-up did not show any recurrences.

Table 1. Location of rare case reports indexed in MEDLINE during years 2006-2015.

\begin{tabular}{|c|c|c|}
\hline Location of case reports & Number & Percent \\
\hline Maxilla & 1 & $0.7 \%$ \\
\hline Nasal & 1 & $0.7 \%$ \\
\hline Ribs & 1 & $0.7 \%$ \\
\hline Sacrum & 1 & $0.7 \%$ \\
\hline Coccyx & 2 & $1.5 \%$ \\
\hline Cuboid bone & 2 & $1.5 \%$ \\
\hline Scapula & 2 & $1.5 \%$ \\
\hline Odontoid process & 3 & $2.2 \%$ \\
\hline Calcaneus & 4 & $3.0 \%$ \\
\hline Great toe & 4 & $3.0 \%$ \\
\hline Patella & 5 & $3.7 \%$ \\
\hline Ankle & 7 & $5.2 \%$ \\
\hline Cervical spine & 7 & $5.2 \%$ \\
\hline Skull & 10 & $7.5 \%$ \\
\hline Acetabulum & 12 & $9.0 \%$ \\
\hline Phalanxes & 13 & $9.7 \%$ \\
\hline Talus & 13 & $9.7 \%$ \\
\hline Jaw & 14 & $10.4 \%$ \\
\hline Mandible & 16 & $11.9 \%$ \\
\hline Wrist & 16 & $11.9 \%$ \\
\hline Total & 134 & $100.0 \%$ \\
\hline
\end{tabular}




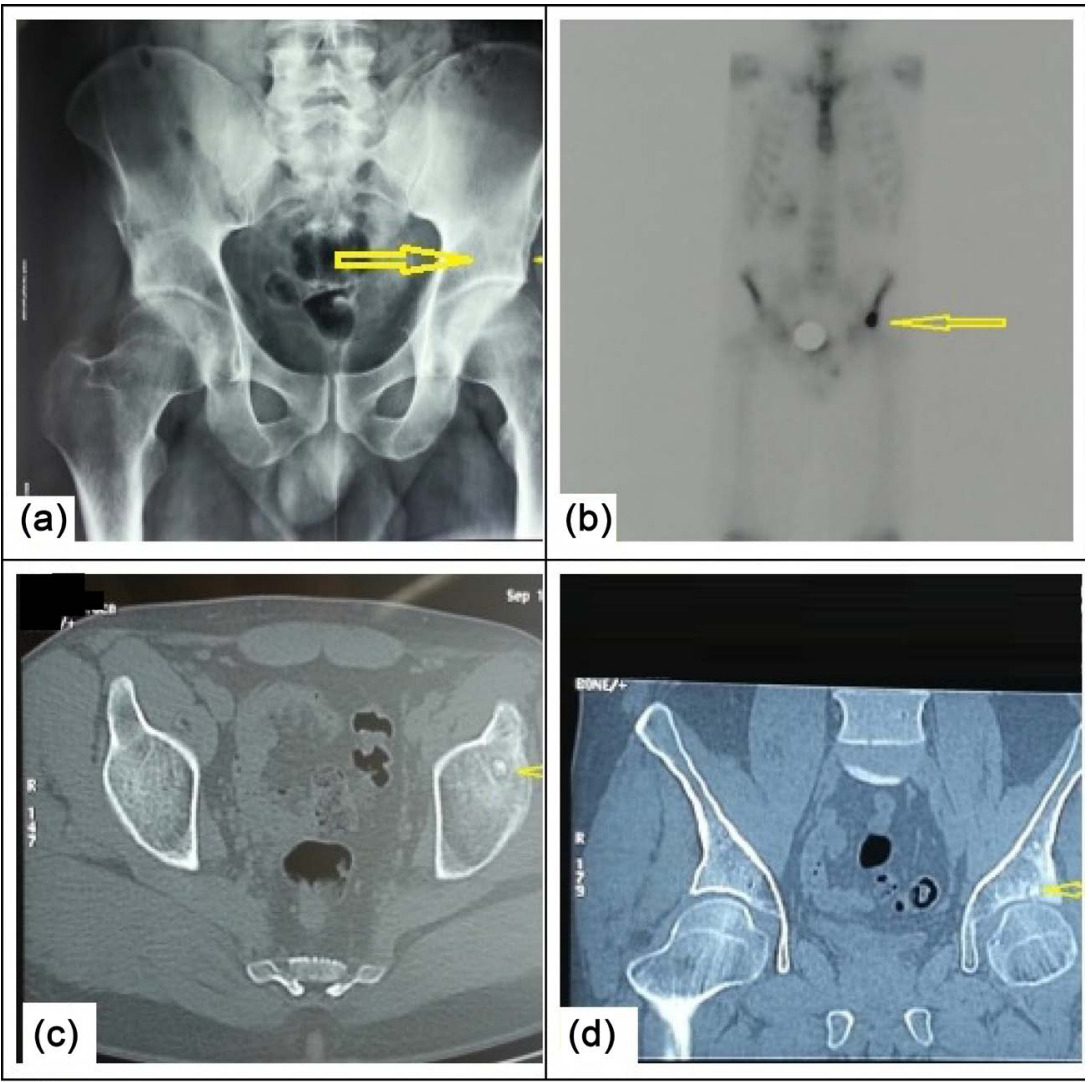

Figure 1. Plain radiographies showed increased bone density in the left acetabular roof (a). A technetium $99 \mathrm{~m}$ bone-scan revealed focally increased uptake in the same area (b). Axial and coronal computed tomography (CTS) of the pelvic revealed a hyperdense nidus of $10 \mathrm{~mm}$ in diameter $((\mathrm{c}),(\mathrm{d}))$.

Figure 1(a) shows the anteroposterior radiograph showing increased bony density in the left acetabular roof. Figure 1(b) shows the focally increased uptake in the region of the acetabular roof.

Figure 1(c), Figure 1(d) show the axial and coronal sections.

Figure 1(d) shows the Computed Tomography Scan (CTS) of the left hip revealed the hyperdense nidus in the acetabular roof.

The second case was a 21-year-old male patient who suffered from coccygeal pain for 2 years. The pain was worsening at night and was improved by aspirin. The physical examination revealed tenderness around coccygeal region. Plain films were normal. The bone scan revealed increased uptake at coccyx (Figure 2(a)). Computed Tomography Scan (CTS) coronal images of the coccyx show a hypodense lesion with central hyperdensity (Figure 2(b)). Sagittal MR imaging show bone marrow edema in the first coccygeal segment (Figure 2(c)).

The third case was a 20 -year-old male who presented chronic nocturnal pain at the left toe, persistent throughout the last years, the pain was improving by NSAID.

In physical examination there was swelling and tenderness on the left toe. The bone scan revealed increased uptake at distal phalanx of left toe (Figure 3(a), Figure 3(b)). 
Computed Tomography Scan presented a hyperdense lesion, surrounding by hypodensity on plantar surface of distal phalanx.

The patient experienced full resolution of symptoms after surgery.

The fourth case was a 27-year-old man who presented with back pain during a l-year period, the pain was mainly at night. Spine plain films were normal, only showed a thoracolumbar scoliosis (Figure 4(a)).

Computed tomography showed a focal increased density at the body of the $12^{\text {th }}$ thoracic vertebra with a hyperdense nidus that surrounded by a ring like hypodensity (Figure 4(b)).

Magnetic Resonance Imaging showed edema of the $12^{\text {th }}$ thoracic vertebrae (Figure 4(c), Figure 4(d)).

The hack pain was subsided immediately after the surgical excision of the nidus.
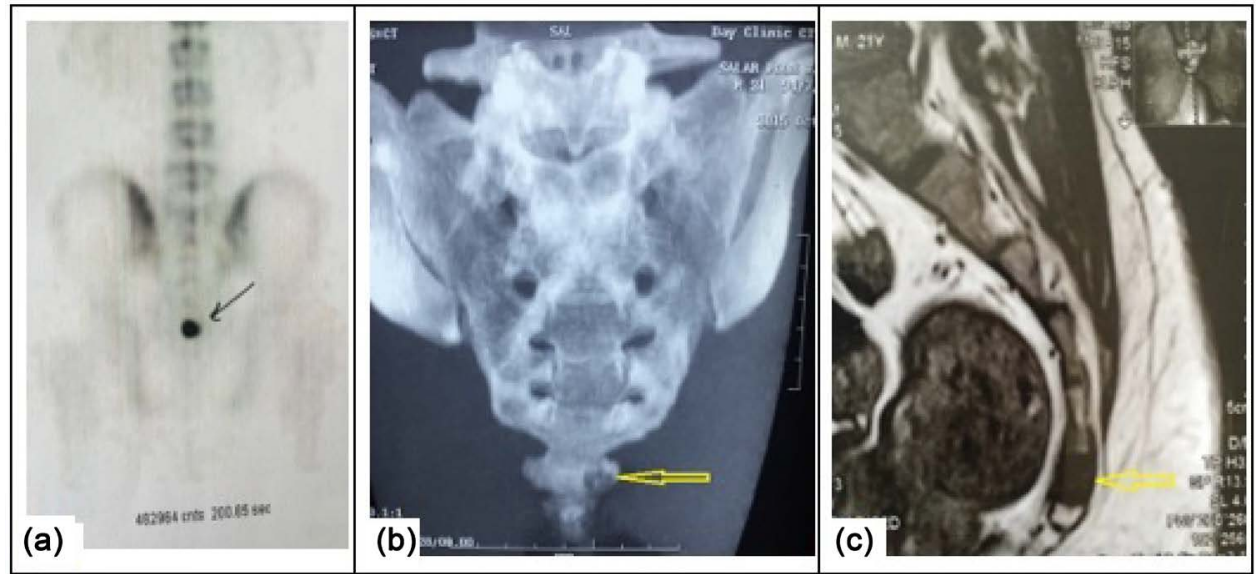

Figure 2. Bone scan showing increased uptake at coccyx (a), Computed Tomography Scan (CTS) coronal images of the coccyx show a hypodense lesion with central hyperdensity (b), Sagittal MR imaging show bone marrow edema in the first coccygeal segment (c).

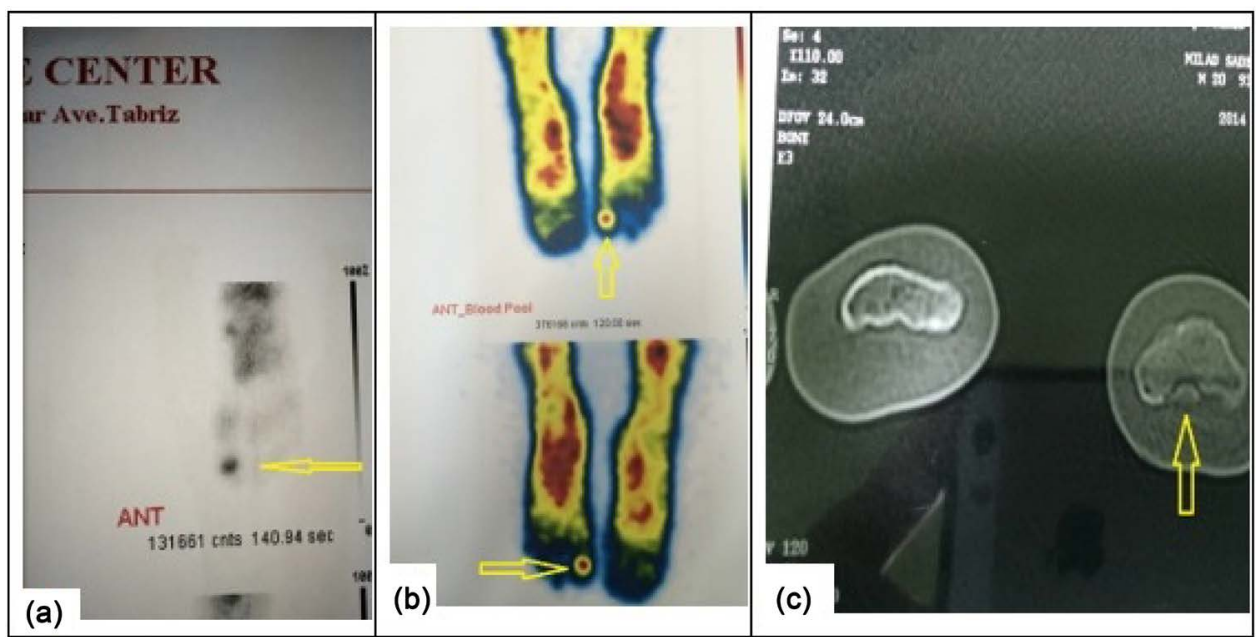

Figure 3. Bone scan showing the increased uptake at distal phalanx of left toe ((a), (b)), Computed Tomography Scan presents a hyperdense lesion, surrounding by hypodensity on plantar surface of distal phalanx (c). 

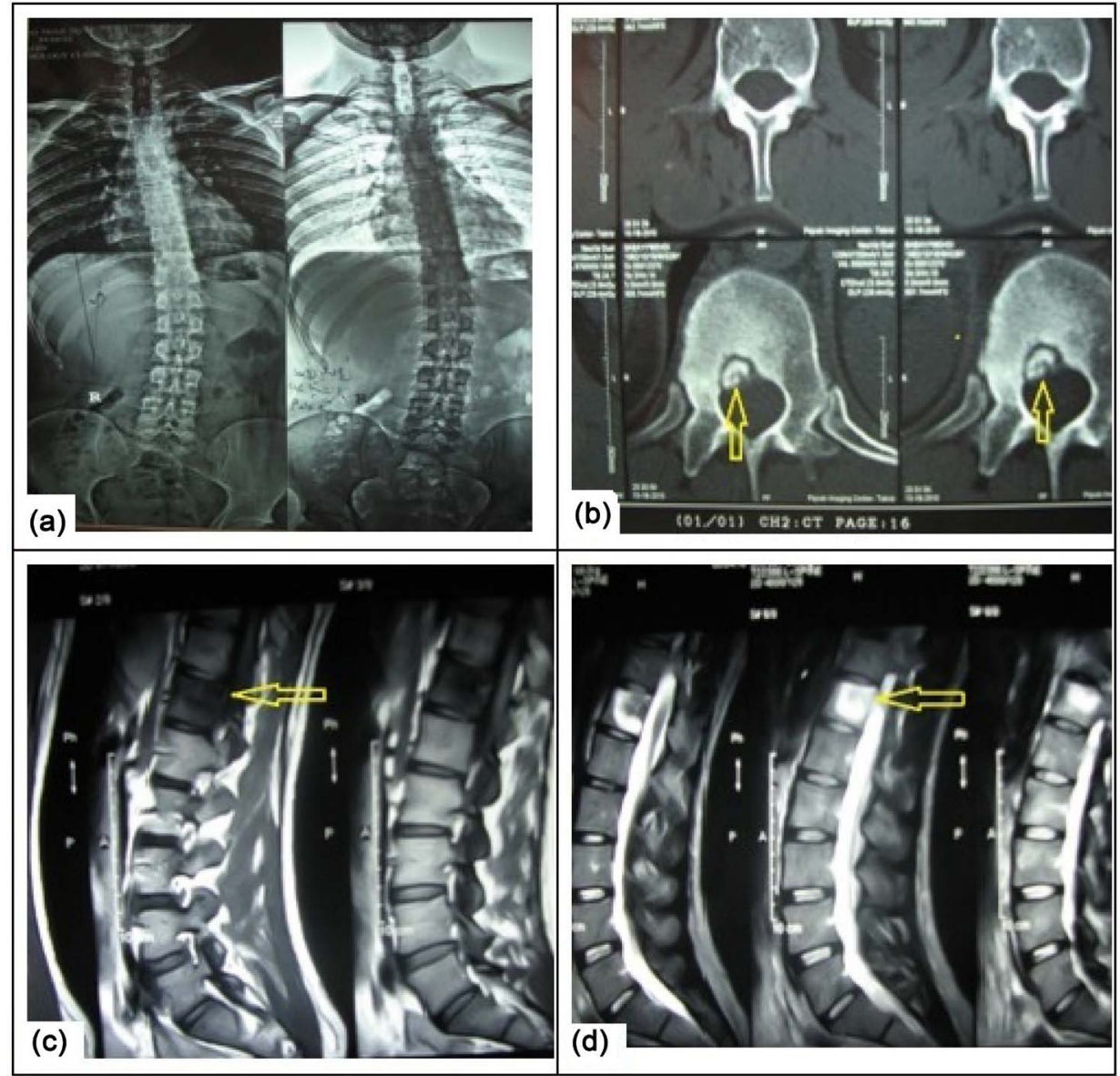

Figure 4. Spine plain films shows a mild thoracolumbar scoliosis (a), Computed Tomography Scan shows a focal increased density at the body of the $12^{\text {th }}$ thoracic vertebra with a hyperdense nidus that surrounded by a ring like hypodensity (b), Magnetic Resonance Imaging shows edema of the $12^{\text {th }}$ thoracic vertebrae $((c),(d))$.

The fifth patient was a 33-year-old female patient with chronic right radicular shoulder pain for 4 years. Pain was decreasing during day times and was increasing at nights.

Physical examination indicated tenderness around shoulder with painful external rotation.

Shoulder plain films were normal, the bone scan revealed obvious increased uptake at super lateral angle of scapula (Figure 5(a)). The Ct. Scan showed relatively ossified 1 $\mathrm{cm}$ nidus with mid peripheral hyper density (Figure 5(b), Figure 5(c)).

As shown in Table 1 from a total number of 134 rare case reports of osteoid ostema indexed in MEDLINE, the osteoid osteoma in Mandible and Wrist were the most frequented osteoma osteoid whereas Maxilla, Nasal, Ribs, Sarcrum and Coccyx were the rarest rare of case reports about osteoid osteoma in MEDLINE.

\section{Discussion}

Osteoid osteoma is a benign osteogenic bone tumor. The term osteoid ostema was introduced into the medical literature first in 1935 by Jaff, describing five benign osteob- 
lastic tumors composed of osteoid and atypical bone. Several authors [8] [9] have demonstrated that prostaglandins can stimulate bone formation, it is possible the large amount of prostaglandins are being produced by osteoid ostoma, and may induce the reactive production of heterotopic bone in the tissues surrounding the lesion. The differential diagnosis of an osteoid ostema includes osteomyelitis, eosinophilic granuloma, healing fracture, ewing sarcoma or osteogenic sarcoma. The tumor may regress spontaneously. The mechanism of procedure is still not precisely known.

The typical form of osteoid osteoma in radiological findings is highly indicative for diagnosis. Sometimes osteoid osteoma manifests atypical both clinically and on imaging, resulting in delayed diagnosis. The most common and classic location of the lesion is within the cortex of the long bones e.g. tibia [8]. The clinical signs of osteoid osteoma are well-known. Patients classically give a history of pain that worsens at night and are relieved by non-steroid anti-inflammatory drugs (NSAID).

Osteoid osteoma may occur in virtually any bone, more than $50 \%$ of tumor happening in the femur and tibia. The spine is relatively unusual localization of osteoid osteoma and the coccyx seems to be the rare form. Based on the result of our literature review, only two cases of osteoid osteoma in coccyx were reported during the last decade (Table 1). The report of Rajhi $\mathrm{H}$ et al. [10] was in consistence with our study, they stressed that their literature review led to one osteoid osteoma of the coccyx in a young man.

Approximately $10 \%$ of osteoid osteoma are equally distributed between spine, hand, foot, and wrist. When osteoid osteoma occurs in the spine the most commonly affected area is the lumbar spine typically involving the neural arch.

Our literature review in MEDLINE database during years 2006-2015 revealed that the osteoid osteoma seldom involves the Maxilla, Nasal bone, Ribs, Sacrum. Only one sample from each of them has been reported through the last decade.

\section{Conclusion}

Analysis of our study indicated that the physicians should bear in mind the probability
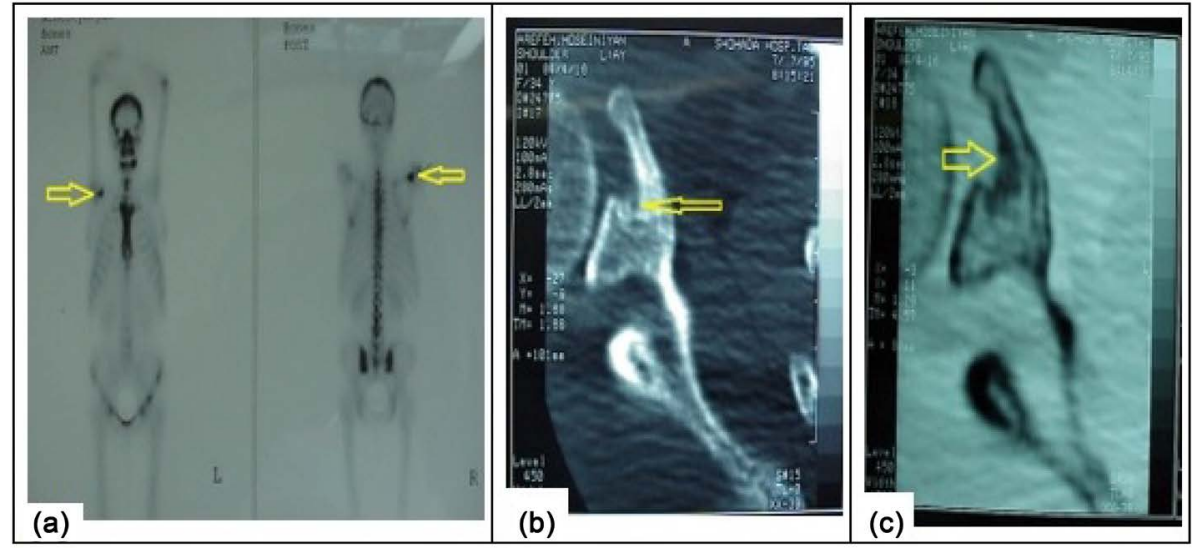

Figure 5. Bone scan shows increased uptake at superolateral angle of scapula (a), Computed Tomography Scan (CTS) shows relatively ossified $1 \mathrm{~cm}$ nidus with mid peripheral hyper density ((b), (c)). 
of osteoid osteoma, when they are considering the chronic pain in the atypical areas of patients' body.

\section{Conflict of Interest}

The authors declare that they have no conflict of interest. They declare also that they have no financial interests related to the material in the manuscript.

\section{Ethical Approval}

All procedures performed in studies involving human participants were in accordance with the ethical standards of the institutional and/or national research committee and with the 1964 Helsinki declaration and its later amendments or comparable ethical standards.

\section{Informed Consent}

Informed consent was obtained from all individual participants included in the study.

\section{References}

[1] http://orthoinfo.aaos.org/topic.cfm?topic=A00507

[2] Biglu, M.H., Ghavami, M. and Biglu, S. (2014) Authorship, Institutional and Citation Metrics for Publications on Postmenopausal Osteoporosis. Osteoporosis International, 25, 1337-1343. http://dx.doi.org/10.1007/s00198-013-2603-3

[3] Jaffe, H.L. (1953) Osteoid-Osteoma. Proceedings of the Royal Society of Medicine, 46, 1007-1012.

[4] Canella, C. (2015) Osteoid Osteoma: Diagnosis and Treatment. Radiologia Brasileira, 48, v-v. http://dx.doi.org/10.1590/0100-3984.2015.48.4e1

[5] Khan, A.N., Chandramohan, M., Turnbull, I. and Macdonald, S. (2005) Osteoid Osteoma. http://www.emedicine.com/radio/topic498htm

[6] Durak, K., Ersozlu, S., Bayram, S., Ozturk, C. and Temiz, A. (2005) Osteoid Osteoma of the Sternum. European Journal of Orthopaedic Surgery \& Traumatology, 15, 233-236. http://dx.doi.org/10.1007/s00590-005-0233-y

[7] Singh, J.P., Srivastava, S. and Singh, D. (2015) Osteoid Osteoma Masquerading Tubercular Arthritis or Osteomyelitis on MRI: Case Series and Review of Literature. The Indian Journal of Radiology \& Imaging, 25, 261. http://dx.doi.org/10.4103/0971-3026.161447

[8] Pourfeizi, H.H., Sales, J.G., Elmi, A. and Tabrizi, A. (2012) Osteoid Osteoma of a Scapula: A Case Report in a 34 Years Old Woman. Medical Journal of the Islamic Republic of IRAN, 26, 143-146.

[9] Durak, K., Ersozlu, S., Bayram, S., Ozturk, C. and Temiz, A. (2005) Osteoid Osteoma of the Sternum. European Journal of Orthopaedic Surgery \& Traumatology, 15, 233-236. http://dx.doi.org/10.1007/s00590-005-0233-y

[10] Rajhi, H., Bouzidi, R., Ezzaouia, K., Chammakhi, R., Felfel, M. and Hamza, R. (2006) Osteoid Osteomas of the Coccyx: A Case Report. Author Information. Revue de Chirurgie Orthopedique et Reparatrice de l'Appareil Moteur, 92, 275-278.

http://dx.doi.org/10.1016/S0035-1040(06)75736-1 
Submit or recommend next manuscript to OALib Journal and we will provide best service for you:

- Publication frequency: Monthly

- 9 subject areas of science, technology and medicine

- Fair and rigorous peer-review system

- Fast publication process

- Article promotion in various social networking sites (LinkedIn, Facebook, Twitter, etc.)

- Maximum dissemination of your research work

Submit Your Paper Online: Click Here to Submit

Or Contact service@oalib.com 